\title{
METODE DAN PERTIMBANGAN UNTUK MELEPAS RESTORASI CEKAT SECARA KONSERVATIF
}

\author{
Eri H. Jubhari \\ BagianProstodonsi \\ FakultasKedokteran gigi \\ UniversitasHasanuddin
}

\begin{abstract}
A fixed restoration should be removed because it has distortions at the restoration or its abutment. It's not an easy process, especially when it has been cemented permanently. To do so, it is necessary to know the restoration history, cement, abutment, "' and the method. Some methods for removing the fixed restoration intactly are follow: straight chisel and mallet, excavator, reverse mallet, ATD, peerless crown-a-matic, adhesive method, ligature, Reynold technique andforcep. Altough physical and psychological traumas during the removing process have been prevented, dentist must give adequate informed concent, take care the abutment health and prevent the patient from swallowing the restoration.
\end{abstract}

Key words : fixed restoration, crown remover

\section{PENDAHULUAN}

Restorasi cekat harus dilepaskan untuk diperbaiki karena adanya gangguan struktur atau fungsi-nya. ${ }^{1}{ }^{2}$ Suatu restorasi yang masih layak pakai, harus diusahakan tetap utuh ketika dilepas. ${ }^{3}$ Ada banyak faktor yang mempengaruhi keputusan untuk melepaskan restorasi, umumnya berkaitan dengan penghematan yang dapat dilakukan oleh pasien. ${ }^{4}$

Proses pelepasan restorasi merupakan pengalaman yang tidak 
menyenangkan bagi dokter gigi dan pasien, karena dapat menimbulkan trauma serta mempunyai resiko mencederai gigi dan jaringan lunak, bahkan sampai tercabutnya gigi penyangga. ${ }^{3,4}$

Sebagai pencegahan

permasalahan tersebut, dokter gigi harus mempersiapkan pasien dan dirinya sendiri agar tidak mencederai gigi penyangga dan gingiva. $^{3} \quad$ Untuk mengetahui beberapa cara pelepasan restorasi cekat, pada makalah ini akan dibahas beberapa alat dan pertimbangan untuk melepaskan restorasi cekat secara utuh.

\section{TELAAH PUSTAKA}

\section{Alasan pelepasan}

Faktor penyebab suatu restorasi yang telah disemen permanen harus dilepas, secara umum digolongkan atas faktor biologis dan faktor mekanis. ${ }^{2}$ Penyebab terbanyak adalah faktor biologis, yaitu karies pada gigi penyangga. $^{5}$

Kondisi-kondisi yang harus dipertimbangkan
1. Riwayat restorasi. Jika dokter gigi mempunyai catatan yang adekuat mengenai kondisi gigi penyangga, dan bahan core dan semen, pengambilan keputusan menjadi lebih mudah. Sedangkan jika tidak, operator menjadi serba ragu dan hasil pekerjaan tidak dapat dipastikan, sehingga restorasi lebih baik dirusakkan saja. ${ }^{1,4}$

Cara konservatif umumnya efektif untuk sementasi sementara, sementara sementasi permanen umumnya memerlukan cara radikal. ${ }^{6}$ Sementasi permanen dengan glass ionomer biasanya sangat sulit dilepaskan, lain halnya dengan semen polikarboksilat, dan sengfosfet yang tidak terlalusulit dilepaskan ${ }^{4}$

2. Keinginan pasien. Melepaskan restorasi ceka tanpa merusakkan restorasinya, berpotensi menyebabkan trauma terhadap gigi penyangganya, sehingga sebelum proses pelepasan dimulai, harus diberitahukan mengenai resiko 
yang dapat terjadi. Faktor ini umumnya dipengaruhi oleh kondisi keuangan pasien. ${ }^{14}$.

3. Keadaan gigi preparasi. Risiko pelepasan makin besar jika gigi preparasinya telah dirawat endodontik dan jika makin bahyak gigi preparasinya., Untuk itu disarankan menyimpan datapasien agar diketahui segala sesuatu mengenai restorasi tersebut. $^{4}$

4. Pemilihan cara pelepasan yang tepat. Untuk melepaskan restorasi, kadang-kadang perlu diberikan anestesi ${ }^{6}$ dan setelah itu diikuti dengan penggunaan alatpelepas restorasi. Karena umumnya alat tersebut menggunakan tekanan, tekanan harus diarahkan searah dengan sumbu panjang gigi untuk menghindari fraktur gigi preparasi, dan harus dikontrol agar tidak mencederai gigi lain atau jaringan lunak $k^{1,4}$

\section{Alat pelepasan restorasi}

1. Straight chisel dan mallet. Blade chisel diletakkan di b awah lengkung terbesar atau dikonektor (gambar 1a). Blade tidak boleh diletakkan di tepi servikal restorasi karena restorasi dapat rusak karenannya. Tekanan diberikan searah dengan sumbu panjang gigi ketika chisel diketuk dengna mallet. $^{1}$

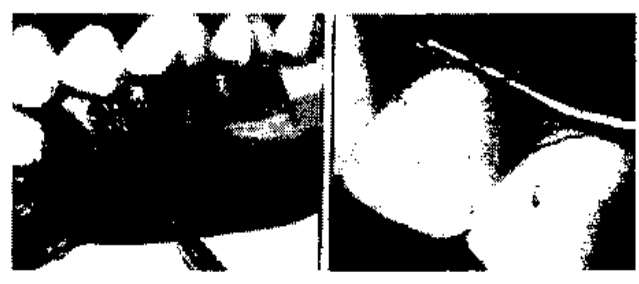

Gambar 1.a.siraigm; cmsei aan manei; D.eKSKavaior (Sumber: Pruitt CO. A review of methods and instrumentation for removing crowns and bridges from prepared teeth. Gen Dent 1994;4:3206) ${ }^{1}$.

2.Ekskavator. Blade ekskavator diletakkan dibawah titik kontak (gambar 1 b) atau di bawah konektor, kemudian ditarik ke atas atau ke bawah.

3.Reverse mallet (metode sliding weight). Alat ini sebenarnya untuk melepaskan restorasi yang disemen sementara. ${ }^{1,3}$ Alat ini bekerja dengan adanya peluncuran beban (sliding weight). Ada beberapa jenis reverse mallet, antara lain:

a. Clevedent (gambar 2), yang 
terdiri dari batanglogam, sliding weight dan beberapa tip yang dikait di tepi restorasi atau di celah interproksimal. ${ }^{1,36}$ Jika tip telah terkait, sliding weight dilepaskan/ditarik. ${ }^{3} \quad$ Alat ini sebaiknya digunakan pada kedua ujung GTJ, dan tidak digunakan untuk memulai proses pelepasan.'- ${ }^{3}$ Resiko rusaknya restorasi dapat dikurangi dengan melilitkan kawat kuningan di celahinterproksimal (gambar 3). ${ }^{6}$

b. Instrumen ATD, mempunyai kawat baj a yangfleksibel, berbentuk ayunan, dan digantung di

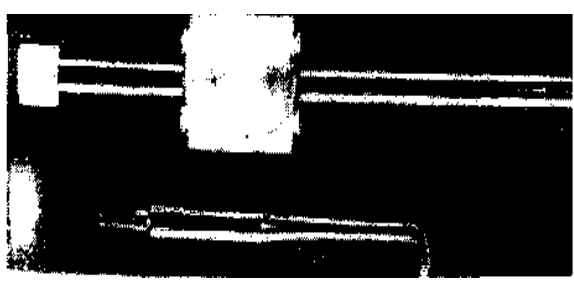

Gambar2.Sliding weight.(Sumber: Breeding LC, Dixon DL. Diagnosis and management of urgent restorative problems. In: Falace, editor. Emergency dental care. Baltimore: Williams \& Wilkins; 1995. p. 171-6) ${ }^{6}$

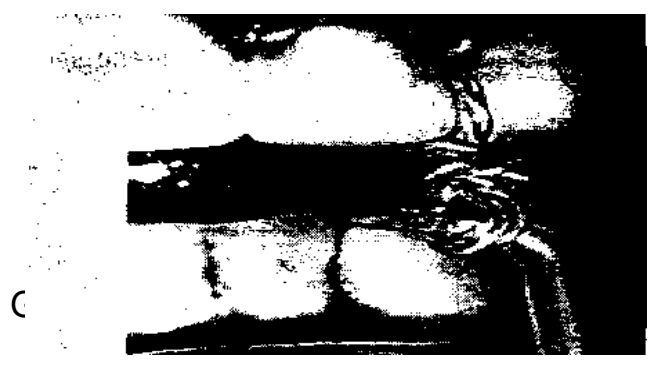

mahkota (Sumber: Breeding LC, Dixon DL. Diagnosis and management of urgent restorative problems. In: Falace, editor. Emergency dental care. Baltimore: Williams \& Wilkins; 1995. p. 171-

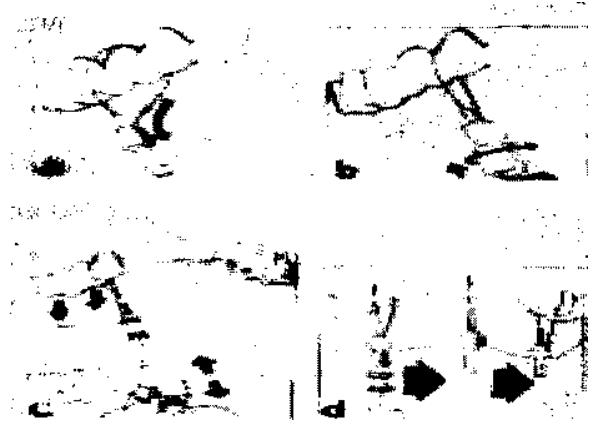

Gambar 4. Pelepas GTJ jenis ATD, a.ligatur melilit konektor, b.ligatur dipasang di ujung penarik, creverse hammer diaktifkan, d.beberapa lokasi penarikan (Sumber: Pruitt CO. A review of methods and instrumentation for removing crowns and bridges from prepared teeth. Gen Dent 1994;4:320-6). ${ }^{1}$

sekeliling konektor (gambar 4). ${ }^{1}$ ${ }^{6}$ Ayunan ini yang akan berkait dengan tip. ${ }^{14,6}$ Cara ini lebih aman dari pada reverse mallet yang digunakan tanpa kawat. '-6 Ksberhasilan dan keamanan alat ini sangat memuaskan, terlebih jika memasang compound panas pada retainer selama 60 detik agar terjadi ekspansi pada restorasi. ${ }^{4}$

4. Peerless crown-a-matic, bekerja dengan adanya tiap dan 3 macam daya pegas (gambar 5a). ${ }^{1,6}$ 
Instrumen ini dipegang dengan satu tangan, sejajar dengan sumbu panjang gigi, sementara tangan yang lain memegang tip yang berada dibawah konektor. ${ }^{1}$ Penggunaan pegas secara maksimal menuntut pertimbangan yang matang, karena kekuatannya lebih besar dan berlangsung lebih cepat dibanding sliding weight. ${ }^{1,6}$.

Instrumen E-type (gambar 5b), serupa dengan peerless crowna-matic, tetapi mempunyai motor yang mengontrol frekuensi dari intensitas hentakan. ${ }^{1=}$.

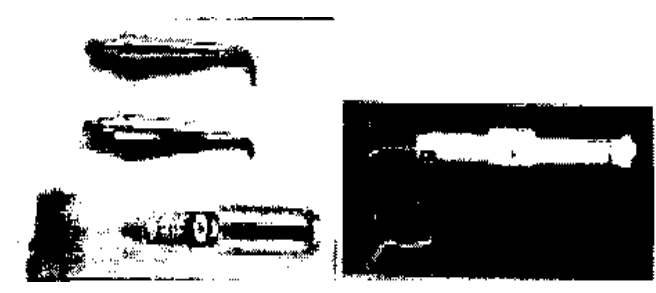

Gambar 5a.Peerless crown-a-matic, b.Pelepas mahkota E-type (Sumber: Pruitt CO. A review of methods and instrumentation for removing crowns and bridges from prepared teeth. Gent 1994;4:320-6)1.

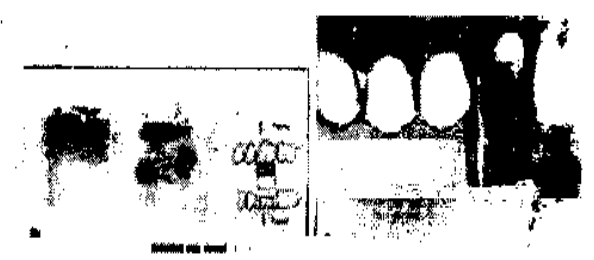

Gambar 6. Metode Richwill, b. Penggunaan copper band dan bahan compound (Sumber:Pruitt CO.A review of method and instrumentation for removing crown and bridges from prepared teeth. Gen dent 1994;4:20$6)^{1}$.

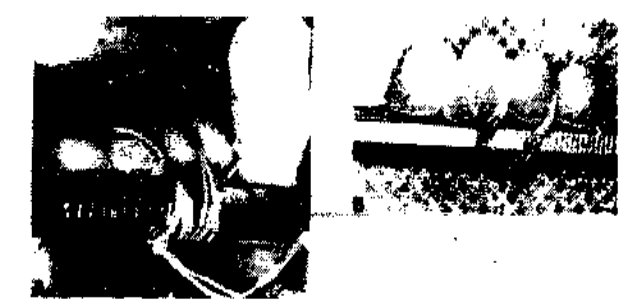

Gambar 7.Teknik Reynolds, a. Pegangan kaca mulut dililit ke GTJ dengan floss, b.GTJ terlepas (Sumber: Breeding LC, Dixon DL. Diagnosis and management of urgent restorative problems. In: Falace, editor. Emergency dental care. Baltimore: Williams \& Wilkins; 1995.p. $171-6)^{6}$

\section{Metodesticky(adesif)}

a. Richwil, menggunakan resin adesif,' yang lunak jika direndam dalam air panas selama 1-2 menit. ${ }^{16}$ Caranya, balian tersebut digigit selama 8-10 detik hingga menutupi 2/3 bagian restorasi, lalu pasien diinstruksikan untuk membuka mulut dengan cepat (gambar 6a). Cara ini biasanya efektif untuk GTJ yang kurang dari 3 gigi penyangga

b. Copper band dan compound. Band yangukurannya sedikit lebih besar dari restorasi dipasang di mahkota yang akan dilepas yang telah 
diulasi varnish. Permukaan proksimal band dibentuk sesuai dengan interdentalnya (gambar 6b). Kemudian band diisi dengan compound yang sudah lunak Setelah dingin, dengan melubangi oklusal band sebagai tempat lewatnya kawat, kawat ditarik hingga restorasiterlepas. ${ }^{1}$

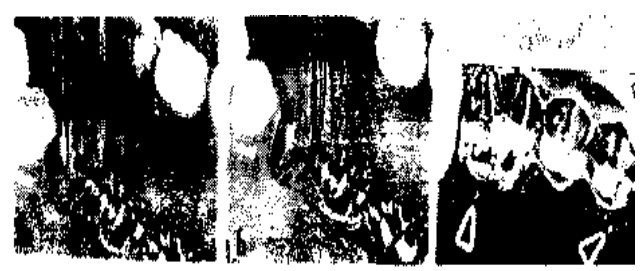

Gambar 8a. Tang Howe menjepit mahkota, b.Forsep hemostatik menjepit di daerah konektor c.Button (tanda panah) di lingual GTJ (Sumber: Pruitt CO. A review of methods and instrumentation for removing crowns and bridges from prepared teeth. Gen Dent 1994;4:320-6) ${ }^{1}$.

6. Ligatur.' Idealnya untuk restorasi sementara. Dua helai kawat ortodontik berdiameter 0,010 inci, panjang 10-12 inci digunakan bersama 3-4 buah spons berukuran $2 \times 2$ inci dan pegangan kaca mulut. Syarat pengungkitan cara ini ialah adanya gigi tetangga sebagai tumpuan padamesial dan distal GTJ.
Caranya,

kawat dililitkan secara ketat di bawah konektor, pegangan kaca mulut dan permukaan oklusal restorasi yang diantarai oleh spons. Posisi pegangan kaca mulut diatur sejajar dengan dataran oklusal karena tekanan harus sejajar dengan sumbu panjang gigi.
a. Teknik
Reynolds ${ }^{6}$.

Pegangan kaca mulut dililitkan ke GTJ dengan benang melalui konektor. Gigi di sebelah distal GTJ, menjadi tumpuan ketika dilakukan tarikan, dengan memasang gulungan kapas diantara gigi dan pegangan kaca mulut (gambar 7). Jika tidak ada titik tumpu, pegangan instrumen ditarik dengan satu atau dua jari.

b. Removal buttons', adalah bentukan seperti kancing pada mahkota (gambar 8a). Bulatan malam berukuran 16-gauge dilekatkan di $\quad 1 / 3$ gingival pemukaan lingual atau fasial restorasi. 


\begin{abstract}
Restorasi yang disemen
sementara dikaitkan dengan

skaler atau ekskavator. Kancing

dihilangkan setelah mahkota

disementasi tetap.

7. Forsep dan tang. Alat ini digunakan dengan cara

mencengkeram dan menggoyang restorasi (gambar 8b,c).' Tang ini dapat juga digunakan dengan cara menarik lilitan kawat di bawah konektor. Caranya, satu tang dibawah mencengkeram lilitan ujung kawat, tang yang ditengah menahan lengkungan kawat pada posisinya, lalu kawat ditarik dengan tang tersebut. ${ }^{7}$
\end{abstract}

\section{DISKUSI}

$$
\begin{aligned}
& \text { Permasalahan utama proses } \\
& \text { pelepasan restorasi adalah } \\
& \text { terjadinya kegagalan perawatan, } \\
& \text { sehingga membuang waktu dan } \\
& \text { biaya serta menimbulkan trauma } \\
& \text { pada gigi preparasi. Meskipun } \\
& \text { restorasi tersebut dapat dilepaskan, } \\
& \text { ingatan pasien pada proses } \\
& \text { pelepasan yang rumit akibat } \\
& \text { pelepasan itu tetap ada. Oleh } \\
& \text { karena itu, dokter gigi harus berhati- }
\end{aligned}
$$

hati agar tidak terjadi fraktur gigi preparasinyaa, cedera pada jaringan lunak ataupun trauma psikologis yang berlebihan. ${ }^{3}$

Ujung skaler yang telah ditumpulkan sangat efektif untuk melepaskan restorasi yang disemen sementara. Instrumen tersebut dipasang di tepi gingival permukaan bukal atau lingual mahkota. ${ }^{3}$ Meskipun demikian, restorasi cekat multkinit, sulit dilepaskan dengan hand instrument Malah pemberian hentakan yang terlalu keras dengan alat reverse mallet dapat menyebabkan gigi preparasi mengalami fraktur.

Resiko lainnya adalah tertelannya restorasi. Sebagai pengamanan untuk mencegah tertelannya restorasi, hendaknya meletakkan tampon di aspek lingual restorasi atau dengan melilitkan benang gigi di bawah dan sekeliling GTJ. ${ }^{3}$

Restorasi yang telah disemen permanen biasanya sulit dilepaskan. Sementasi dengan seng fosfat, paling mudah dilepas dibanding dengan semen jenis lain. 
Sedangkan semen glass ionomer adalah semen yang daya adesifnya baik, karena itu sangat sulit dilepaskan dengan utuh. Lain halnya dengan mahkota yang belum disemen permanen, umumnya tidak terlalu sulit dilepaskan.

Resiko fraktur pada gigi preparasi harus selalu diberitahukan terlebih dahulu kepada pasien. Jika ada keraguan mengenai kondisi gigi preparasi atau restorasinya susah dilepaskan, sebaiknya restorasinya dipotong saja. Seorang operator harus dapat memilih antara melepaskan atau memotong restorasinya. Jadi meskipun ada cara yang aman untuk melepaskan restorasi, dokter gigi harus tetap berhati-hati. ${ }^{1}$ Hal ini disebabkan adanya tujuan utama perawatan (selain memperbaiki restorasi) adalah menjaga gigi preparasinya.

Beberapa pertimbangan praktis sewaktu melepaskan restorasi yang telah disemen permanen: ${ }^{3}$

1. Penggunaan reverse mallet sebenamya tidak efektif sebelum mahkota dibelah. Meskipun demikian, setelah dibelah, pelepasan tetap mesti dilakukan dengan hati-hati, $T$

2. Komponen restorasi dapat diperbaiki tanpa perlu melepaskan keseluruhan restorasi,

3. Beberapa prosedur pelepasan tampaknya mudah, tetapi tidak bila dikerjakan. Sebagai contoh, metode penggunaan benang gigi, kawat atau penjepit kertas di bawah pontik untuk menghasilkan daerah untuk mengaplikasikan reverse mallet jarang berhasil,

4. Sebagai tindakan pengamanan selama prosedur pelepasan, sehelai benang gigi dililitkan di sekeliling restorasi sebelum pemberian tekanan.Ujung dari dental floss harus berada di luar mulut. Gumpalan tampon dapat juga diletakkan di lingual dari restorasi.

\section{KESIMPULAN}

Sebuah restorasi yang tidak 
rusak setelah dilepas, diharapkan dapat dipergunakan kembali. Untuk itu perlu di pertimbangkan kesehatan gigi preparasi, gigi tetangga dan jaringan lunak, dan dokter gigi harus memberitahukan resikonya kepada pasien. Karena pelepasan restorasi cekat umumnya menimbulkan trauma.

Beberapa pertimbangan sebelum memulai pelepasan adalah riwayat restorasi, keinginan pasien. keadaan gigi penyangga, dan alat pelepasan yang akan digunakan.

Metode untuk melepaskan restorasi cekat secara utuh adalah straight chisel dan mallet ekskavator, reverse mallet, clevedent, ATD, peerless crown-amatic, instrument E type, metoosticky, Ugatur, teknik Reynolds, removal buttons, serta forsep dan tang.

Beberapa akan pengamanan agarrestorasi tidak tertelan adalah meletakkan tampon di aspek lingual restorasi, dan melilitkan benang di sekeliling mesial dandistal GTJ. Selain itu, diperlukan pengetahuan dan pengalaman agar dapat memilih secara tepat teknik pelepasan sehingga diperoleh hasil yang diinginkan.

\section{DAFTARPUSTAKA}

1. Pruitt CO. A review of methods and instrumentation for removing crowns and bridges fromprepared teeth. GenDent 1994;4:32-6.

2. SelbyA.Fixed prosthodontics failure:areviewanddis-cussion of important aspects. Aust Dent J1994; 39:150-6.

3. HomHR. Practical concideration for successful crown and bridge therapy. Philadelphia: W.B. Saunders; 1976. p.221-2,246-54

4. Christensen GJ. Removing a partially loose fixed prosthesis. J Am DentAssoc 1998; 129:1135

5. Glantz $P$ J, Nilner K, Jendresen D, Sundberg H. Quality of fixed prosthodontics after 15 years. Acta Odontol Scand 1993; 51:247-52.

6. BreedingLC,DixonDL.Diagnosis and management of urgent restorative problems. In: Falace, editor : Emergency dental care. 
Baltimore: Williams \& planning andmakWilkins1995.p. 171-6. ingaovmardbridges.London:Marti

7. SmithBGN. Dentistry inpractice: nDunitz; 1986. p. 213-21 